\title{
Krukenberg tumor in a patient treated with biologics for psoriasis
}

\section{Anca Chiriac ${ }^{1,2,3}$, Piotr Brzezinski ${ }^{4,5}$}

\begin{abstract}
${ }^{1}$ Apollonia University, Department o Physiology-Dermatology, Iasi, Romania, ${ }^{2}$ Nicolina Medical Center, Departemt of dermatology, Iasi, Romania, " "P.Poni” Institute of Macromolecular Chemistry, Romanian, ${ }^{4}$ Institute of Biology and Environmental Protection, Pomeranian Academy, Slupsk, Poland, ${ }^{5}$ Department of Dermatology, Provincial Specialist Hospital in Slupsk, ul. Mickiewicza 12, 76-270 Ustka, Poland
\end{abstract}

Corresponding author: Prof. Anca Chiriac, E-mail: ancachiriac@yahoo.com

Sir,

Krukenberg tumor (KT) is, by definition, any ovarian metastatic carcinoma derived from a primary malignancy [1]. The name of the malignancy, that can create confusion in clinical practice, belongs to Friedrich Ernst Krukenberg who described a new form of ovarian cancer in 1896, which proved, to be metastatic, 6 years later [2].

It has been evidenced lately the origin of the KT could be, in most cases, gastric and colorectal cancers, but also other sites have been reported, such as breast, small intestine, lung, gallbladder and biliary ducts, urinary tract, pancreas, uterine cervix $[2,3]$.

KT has been considered a rare type of ovarian malignancy, occurring in $1 \%-2 \%$ of patients, with a higher incidence in China, Korea and Japan, affecting females of all ages, but preferentially during premenopause period [1].

We report a case of 60-year-old female patient, who has been treated, for more than 10 years, with adalimumab for a severe plaque psoriasis and psoriatic arthritis, with close follow-up, every 6 months and good clinical evolution. Suddenly, in the absence of any previous symptoms, she was hospitalized in Emergency for abdominal and pelvic pain, bloating and anorexia. She was transferred to Oncology Department for investigations, computed tomography revealed large bilateral ovarian solid masses and huge ascites, associated with very high levels of serum CA-125. She died within hours after admission at the hospital, family did not accept necropsy. A diagnosis of KT was supposed.

Particularities of present case are the following: a menopause woman, treated with biologics for many years for psoriasis, evaluated carefully at every 6 months, who was diagnosed with KT.

Searching medical data base there is no report of $\mathrm{KT}$ diagnosed in a patient treated with biologics for psoriasis. Could it be a coincidence or more? Long-term cancer risks with anti-TNF therapies should be a concern for all physicians and any case should be reported.

\section{Consent}

The examination of the patient was conducted according to the Declaration of Helsinki principles.

\section{REFERENCES}

1. Qiu L, Yang T, Shan XH, Hu MB, Li Y. Metastatic factors for Krukenberg tumor: a clinical study on 102 cases. Med Oncol. 2011;28:1514-9.

2. Bennett JA, Oliva E. Pathology of the adnexal mass. Clin Obstet Gynecol. 2015;58:3-27.

3. Muthukrishnan S, Naganathbabu OL, Murugesan SD, Srinivasan UP, Amudhan A, Rajendran S. Krukenberg tumours from gastrointestinal cancers-analysis from a tertiary care centre in India.J Gastrointest Oncol. 2018;9:1164-7.

Copyright by Anca Chiriac, et al. This is an open access article distributed under the terms of the Creative Commons Attribution License, which permits unrestricted use, distribution, and reproduction in any medium, provided the original author and source are credited.

Source of Support: Nil, Conflict of Interest: None declared.

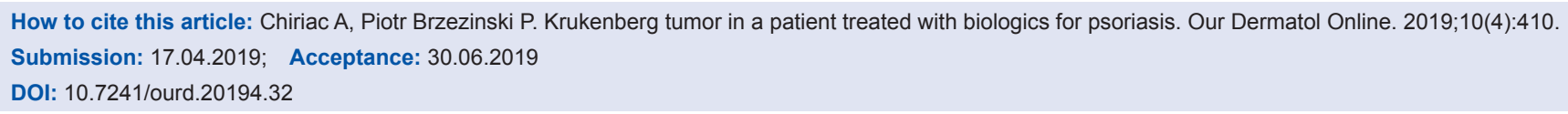

